\title{
A Study on the Relationship between Flow Theory and Yoga Therapy and its Effects on Coping with Stress
}

\author{
Akshada Vivek Kulkarni ${ }^{1}$, Reshma Murali ${ }^{2}$, Archana Patki ${ }^{3}$ \\ ${ }^{1}$ Post graduate student \\ ${ }^{2}$ Assistant Professor \\ ${ }^{3}$ Professor and Head \\ Department of Psychology, Smt Maniben M.P. Shah Women's College of Arts and Commerce, Mumbai \\ Email - reshma.smurali@gmail.com \\ Corresponding author-Ms. Reshma Murali
}

\begin{abstract}
Introduction: Flow has been expressed more as an experience than as a concept. Its surreal explanations have made individuals curious to experience and learn more about it. The flow theory attempts to describe the concept based on its characteristics thus making it easier to understand and measure. Stress yet another subjective experience which is used variably by individuals to describe various life situations. The subjectivity in stress prevails due to peoples changing dynamics of coping with it. Every individual maybe affected differently by a stressor and have different coping styles. One of the coping mechanism widely used by people is the practice of Yoga Therapy. Yoga Therapy is based on set of principles and practices and are reported to help individuals deal with stress.

Methodology: The population was women practicing Patanjali Yoga. The criterion for inclusion was women with high disposition for flow, practicing Yoga at the same class. A sample of 10 women was obtained by screening them based on the Flow Dispositional Scale. Women with high scores on the disposition scale were included. The sample was selected using purposive sampling. Maximum variation approach to sampling was used in order to incorporate a range on participants and to derive richer data.

Results: Participants with high disposition to flow when practicing Yoga could be categorized largely as having normal to mild stress. Thus the findings of the research are in line with the proposed hypothesis stating that flow aids stress coping mechanisms.

Conclusions: All the respondents agreed that the practice of yoga has been facilitative in a number of positive changes in them and thus has had a similar effect of those associated with them. They have stated that the practice of yoga has made them calmer and helps them control their emotions and thoughts. They are more composed when facing difficult situations and has made them into optimistic problem solvers. This stability and attitudinal change has helped them to be available to others not just physically but mentally. They tend to respond and contribute to conversations by being analytical and empathetic.
\end{abstract}

Key Words: Yoga therapy, flow theory, Patanjali yoga, emotions, stress.

(Paper received $-6^{\text {th }}$ June 2017 , Peer review completed $-10^{\text {th }}$ July 2017 , Accepted $-12^{\text {th }}$ July 2017)

\section{INTRODUCTION}

Yoga is essentially a spiritual discipline based on an extremely subtle science, which focuses on bringing harmony between mind and body. It is an art and science of healthy living. The word 'Yoga' is derived from the Sanskrit root 'Yuj', meaning 'to join' or 'to yoke' or 'to unite'. According to yogic scriptures the practice of Yoga leads to a perfect harmony between the mind and body as there is a union of individual consciousness with that of the Universal Consciousness [1]. Yoga is commonly looked upon as a form of 
exercise commonly used for the purpose of physical and mental health. While these can be understood as the natural consequences of practicing yoga, it aims to have far more effects. Yoga aims to help an individual harmonise themself with the universe. It is the technology of aligning individual geometry with the cosmic, to achieve the highest level of perception and harmony [2].

Yoga works on the level of one's body, mind, emotion and energy. Four fundamental paths of yoga have been identified and each individual is seen to be a combination of these paths. The education in regards with yoga has always emphasized on the 'guru-shishya parampara'. The reason is that only a Guru can mix the appropriate combination of the four fundamental paths, as is necessary for each seeker. A number of Yoga Sadhanas are thus been 'practiced by individuals to instill a sense of calm and deal with stress in everyday life. A clear understanding of the various forms of yoga and its effect are been imparted [3].

The whole of idea of practicing yoga and its final goal can thus be summarized as, 'Tadadrastuh svarupe avasthanam'. The mantra states that at the time when an individual is meditating and deeply focused the individual witnesses their own form, the true essence in a state of stability. This moment of self-realization unifies the seer, seeker and seen thus advancing the individual to experience complete happiness [4].

Human beings spend their entire life in seeking happiness and a sense of completion. While reaching the epitome of self-realization, every individual transcends through many a phases. Every phase requires the individual to deal with different challenges as they move forward. The moments of peak experiences consider flow as an essential component. Yoga practices have been seen to help individual deal with the hurdle of stress while moving towards these experiences. This research on the basis of common characteristics between yoga and flow tries to further understand their relationship and effect on an individual's capacity to deal with stress [5].

\section{Flow Theory}

Maslow has espoused a dualistic theory of motivation. According to Maslow motives can be categorized under two broad categories, namely, 'deficiency motives' and 'growth motives'. Maslow however states that considering the complex relations of our motives it is impossible to describe our needs or behaviour in relation to a single distinct drive. Maslow also argues that various human needs differ considerably based on their importance. Some needs have been satisfied to a certain extent while some others may go virtually unnoticed. He therefore favours a general, hierarchical model of human motivation [6].

In his hierarchy of needs Maslow moves from physiological needs to the higher form needs where selfactualization is considered as the highest form of need. Self-actualization can be understood of discovering and fulfilling one's own innate potentials. In his study of those rare individuals who have reached this state of 'full humanness' Maslow found certain common characteristics. Among these characteristics was the frequency of peak experiences. Most self-actualizing individuals reported of having mystical moments which they regarded perfect. During these moments the idea of self is lost in feelings of sublime ecstasy, wonder and awe. These nature of these experiences makes it difficult to describe them unless experienced by other. These peak experiences may ensue from love, sex to moments of creative outburst and profound insights. They may take various forms, however heavenly delight is said to make life worth living. Many questions regarding these peak experiences have been raised and explored for years.

Prominent questions have been regarding its nature, individuals who may or have experienced it and the overall quality of the experience. Individuals who have had such experiences have always stated that they have been in a state of 'flow' when in that moment. Thus understanding the exact nature of this flow became important to gain further detail understanding of these peak experiences. Grappled by these questions and a need to understanding the issue of how do people with their entire focus and in absence of external motivation work and stay in the moment, Csikszentmihalyi worked on the concept of flow. The early research participants described their optimal momentary experiences as being 'in flow' and hence this term was used to describe this phenomena. Three regions of momentary experiences were then identified: 1) flow, where challenges and skills matched; 2) boredom, where challenges and opportunities were too easy relative to skills, and 3) anxiety, where demands increasingly exceeded capacities for action. Thus under flow conditions, perceived challenges or opportunities for action stretch existing personal skills, clear proximal goals and immediate feedback about progress [7-8]. 


\section{YOGA AND ITS EFFECT ON COPING WITH STRESS}

Stress is a negative consequence of modern living. In an age of highly dynamic and competitive world, man is exposed to all kinds of stressors that can affect him on all realms of life. Hans Selye [9] first introduced the term stress into life science. The term stress is derived from the Latin word 'stringere' which means to be drawn tight. Stress is a complex, dynamic process of interaction between a person and his or her life [10].

Stress can be two types, eustress and distress. Eustress is the stress experience in moderation, enough to activate and motivate people so that they can achieve goals, change their environments and succeed in life's challenges. People frequently experience enough stress to hurt their job performance and increase their risk of mental and physical health problems. So, the main focus is more on distress than eustress [11]. Sun salutation (Surya Namaskar) is an ancient Indian method of offering prayers to the rising Sun in the morning. The series of physical postures along with the regularisation of breath aim at a range of mental, physical and spiritual advantages. The Surya namaskar is gracefully combined of a sequence of twelve postings and are to be performed facing east, in order to offer prayers to the rising sun. It has been noted in the scriptures that if performed correctly and regularly it relieves stiffness, revitalizes the body, refreshes the mind and purifies subtle energy channels. [12]

Studies have considered Surya Namaskar to be an aerobic exercise as it involves both static stretching and slow dynamic component of exercise with optimal stress on the cardiorespiratory system. Studies have also assessed the cardio cardio-respiratory and metabolic responses of four rounds of Surya namaskar, a typical amount performed by practitioners, to determine its potential as a training and weight loss tool [13]. In a study by Javdekar and Manjunath, 320 school children between the age group of 12 to 14 years, belonging to both genders were screened and 64 healthy volunteers were selected. They were randomly allocated to 2 groups with 32 students each (Experimental group and Control group). Subjects were assessed at the beginning and end of 30 days of intervention (Surya namaskar or Physical Exercise) using a Digit Letter Substitution Task. The group which practiced Surya namaskar had 16.7\% improvement compared to $13.2 \%$ in physical exercise group. However, the difference between the groups was statistically not significant. The marginal better performance in the Surya namaskar group can be attributed to the aspect of Surya namaskar i.e. Physical activity interspersed and slow breathing and relaxation as mentioned earlier. Hence, the present study speculated that physical activity of any form followed by supine rest can influence the attentional processes [14].

Another area where yoga has found application is health care. Twelve older female dementia patient family caregivers (eight Latinas and four Caucasians) participated in a six-session manualized yogameditation program (called Inner Resources) designed to help caregivers cope with stress. Pre and post comparisons revealed statistically significant reductions in depression and anxiety and improvements in perceived self-efficacy. Average minutes of weekly yoga- meditation practice were significantly associated with improvements in depression. The majority of caregivers found the intervention useful and reported subjective improvements in physical and emotional functioning. These findings suggest that Inner Resources may be a feasible and effective intervention for family caregivers and may improve affect, coping, physical well-being, and stress management [15].

The aim of this study was to ascertain the relationship between flow theory and yoga theory and its roles in the management of stress.

\section{MATERIALS AND METHODS}

\section{Sample}

The population was women practicing Patanjali Yoga. The criterion for inclusion was women with high disposition for flow, practicing Yoga at the same class. A sample of 10 women was obtained by screening them based on the Flow Dispositional Scale. Women with high scores on the disposition scale were included. The sample was selected using purposive sampling. Maximum variation approach to sampling was used in order to incorporate a range on participants and to derive richer data. 


\section{Measures}

1. Dispositional flow scale

2. Interview

3. Depression, Anxiety, Stress Scale (DASS)

\section{Design}

The design of this study was qualitative, exploratory and descriptive in nature. A qualitative study aids in understanding the experiences of the sample under the study and the meanings attributed by them. It is a qualitative research where individuals practicing Yoga will be screened on the basis of their disposition to flow. Individuals would then be divided into two groups namely, the one with the disposition and the one without disposition. The flow questionnaire and stress scale will then be administered to know the difference between their s stress coping responses, if any).

\section{RESULTS}

The scores of 10 respondents on the Disposition Flow Scale were recorded. Participants with scores 13 and above were categorized as having high disposition for flow and were included in the sample for the research. A minimum score of 13 was recorded for 3 participants. Most of the scores varied from 13 to 16, with only one outlier score of 18 . The scores of 10 respondents on the stress scale were also recorded. 7 participants had a score of 9 and below and hence were included in the normal category. 3 participants had scores of 10, 10 and 11 and hence, were included in the mild category. The scores of 10 participants on the Flow Dispositional Scale and Stress Scale were compared. It was observed that participants with high disposition to flow when practicing Yoga could be categorized largely as having normal to mild stress. Thus the findings of the research are in line with the proposed hypothesis stating that flow aids stress coping mechanisms.

\section{DISCUSSION}

The responses of the first question helped in understanding the number of years the respondents had been practicing yoga. The responses varied from 1 year to 16 years. Considering the range of the years of practice it can be assumed that the effects of the yoga had been evaluated and that the responses helped in understanding not just the quality but also the effectiveness of yoga. The age range of these respondents ranged from 45 to 81 years of age thus providing a basic understanding about the age from which women had started practicing yoga. A research conducted by S. Dhivya Laxmi and Dr. K Murigavel (2013) effects of Asanas and Pranayama practices on mood state anxiety and stress on working middle aged women was analysed. The sample consisted of sixty middle aged women age ranged between 35 and 50 years. It was concluded that eight weeks of asanas and pranayama practice significantly reduced in mood state, anxiety and stress of working middle age women.

The second question aimed at understanding the regularity with which the respondents had been practicing yoga. Six women out of ten responded that they practice it every day. The reasons stated by some of the participants who had been successful in practicing it regularly were effectiveness on body by the reduction of pain and increased flexibility and motivation. One respondent had also stated that she regularly played sports before but due to increasing age shifted to yoga, thus emphasizing on the positive effects of physical exercise and yoga. The ones who had been unsuccessful in practicing it regularly stated that they attempted to practice it every day but largely did not succeed. The reasons stated for the same were lack of motivation, lack of time and peaceful setting at home.

The third question dealt with understanding the settings in which the participants practiced yoga. Maximum participants stated that they practiced it at home and at the class. One responded had stated that she practiced it at home on a specific spot. Another respondent had stated that they practiced it by a river, on a terrace and at a holiday home. One respondent had further emphasized on the importance of 
setting by stating that practicing at home becomes difficult because one cannot completely focus and concentrate in certain setting.

The fourth question helped in understanding the various reasons that encouraged the respondents to practice yoga. Respondents had stated positive effects on mind and body had been one of the main reasons to continue the practicing yoga. Changes in lifestyle and its' effects were observed and yoga has been practiced to deal with the stressors of this lifestyle and to reduce its ill effects. While listing the positive effects on their body they had stated that it had made them flexible, improved the functioning of their nervous system, built their muscle strength and made them energetic. They had also stated that they had observed changes in their bodies due to age and this had encouraged them to start and continue practicing yoga. A respondent had also stated that she practices it to keep herself fit and continue looking young and that yoga had also helped her maintain her weight. While listing down the psychological effects respondents had stated that practicing yoga has led them to feel peaceful, calm and composed. This composure was than reflected in their improved problem solving capacities which they had described using terms such as; clearer thinking constructive ways and dealing better with problems. They had also stated that feel in better control of their emotions thus making them mentally empowered. One respondent had also stated that when she managed to practice yoga regularly it gave her a sense of accomplishment thus making her happier. They have also stated it made them feel fresh, rejuvenated and created a positive vibe. A respondent had stated that while dealing with stressors due to demands of everyday life yoga became her gateway to mental freedom. She stated that she enjoyed the freedom this time provided her from all other demands and let her listen to her own body.

The fifth question guided in getting an insight about what the respondents experienced when they practice yoga. The respondents explained this experience as a unification of the mind and body. They had stated that their energies came together thus giving them a sense of balance and positive direction. The feelings of balance created a sense of plateau thus merging thoughts, emotions and bodily functions. They had also emphasized on clarity in thought and being closer to understanding their emotions. Respondents had elaborated on sharpness of their senses which had lead them to pay attention to details which may otherwise be ignored or unnoticed. One respondent had stated that sounds in surroundings seem to be in background and do not affect her. She felt she had been disconnected and time seemed too passed slowly as she is had relished every moment of that experience. Another respondent had however stated that she became more sensitive to the sounds and motion, even as mundane as that of the fans around. Yet another respondent had stated that she experienced light emotions and contrary to the popular belief let her mind wander sometimes instead of focusing it. However even during this free-floating state she had paid attention to the details of the new sensations she had experienced. She stated that she had also used other meditative tools such as sounds she found appealing. These had opened her to newer possibilities, experiences and sensations. This attitude has also been reflected in her everyday work thus leading her to think differently and out of the box.

Responses to question six helped to further quantify the experience while practicing yoga. The respondents were provided with a list of adjectives that would help in structuring their experience. When listing down the adjectives options were created based on the one's which are often used by people to describe their experience of yoga. The assumption was further affirmed when many of the words on the list were also used by the respondents when describing their experience in the previous question. However there were certain words used more often than the others.

All the respondents agreed that they are happy when they had practiced yoga, whereas least number of respondents agreed that they felt creative or had creative bouts attributed to yoga. This quantification was further supported by understanding the overall quality of responses of question five. The respondents had used terms such as enjoying, successful experience, interesting experience and forgetting about worldly matters each of which would lead the respondent to feel happy. On the other hand fewer respondents had used terms that may indicate a creative outbreak during this period though a few terms such as thinking differently and working more constructively had been used.

The seventh question was aimed at understanding if any difference exists between other experiences of the day when compared to that of practicing yoga. Most of the respondents had stated that there is a difference in the experience and have further elaborated on their responses of question five and six. Respondents had 
stated that had considered this time as their personal time-out from their various duties and responsibilities. They attempted to focus on their body, emotions and thoughts. Many of them had stated that this helped them clear their thoughts and understand themselves better. The relaxed and calm state of mind aided them perceive things differently. This made them evaluate things through the day in a more positive frame of mind and assisted them in dealing with the problems effectively and with more determination. A respondent had stated that she made it a point to practice yoga at least for 20 minutes everyday because it is the only time when she had to take no efforts to think. Thus the respondents had differentiated between the experience of yoga and those throughout the day based on its' effects in the moment and also those experienced later.

The eighth question attempted to summarize the experience of the participants by asking if the moments when they practice yoga can be termed as their best moments. Most of the respondents had stated that it could be termed as one of the best moments in the day. Some had even said that it was not a regular observation but when they practised certain Aasans they felt a certain peak in their experiences. One respondent had stated that when she practiced 'Pranayama' she felt fresh and stress free and that maked it the best moment for her when practicing yoga. Other respondents had also listed a few Aasans which they termed as their best moments. The answers given were Surya namaskar, Tadasana, Shavasan and Bramasi. Thus this aided the understanding that not every moment during the practice could be termed as best, however there are certain peak moments during which the respondents experience elevated emotions thus summarizing them as 'best moments.'

Question five to question eight attempted to understand yoga as an overall experience as reported by its practitioners. They defined those moments as best and as one's in which they were completely focused. Some had paid little attention to distracting stimulus while the others were attracted even by the minutest details in their surrounding and themselves. Their body, mind and thoughts were reported to be in a balance with each other thus enhancing their capabilities. The orientation of time was variable. Some respondents had felt that the moment or the overall experience had passed away quickly while others felt that because they had submerged themselves in the experience and had enjoyed every passing moment, time seemed to move slowly.

Question nine further extended the application of the flow experienced in yoga to other activities. A number of respondents had said that the experience in other activities had been similar if not same. The participants had largely responded in reference to their hobbies. It is thus important to first understand how the construct of flow is applied to leisure activities.

The fundamental hedonic nature of leisure helps one to understand why these activities may not be considered to produce an optimal experience when adhering to principles of flow. One such missing component from casual leisure activities is that they may not produce substantial amount of challenge to produce flow. They may also lack the significant sense of control. However research on serious leisure tends to highlight the contrary. Certain autotelic individuals peruse competitive games such as chess, tennis and poker in their leisure time. In such activities difficulty is largely determined by the relative skill level of one's opponent. When paired with inferior opponent it represents low level of difficulty whereas being paired with a superior represents a relatively higher level of difficulty. Individuals engaging in such activities on regular basis seem to be pushing their limits and actively seek opportunities. Active hobbies need an individual to have a sense of control and competence and hence may generate flow [16].

The understanding of nature of flow in serious leisure may highlight the non-flow nature of liberal art hobbies. The nature of these activities, their execution and end goals may vary from serious leisure. Thus they look at understanding and gaining knowledge as the end goals and the execution may not really need any physical execution. However Csikszentmihalyi briefly discusses 'micro-flow activities', or private behaviours intended to relieve everyday boredom (e.g. doodling, reading). They may be conceived of as instances of the play and sensory stimulation types of casual leisure. These Liberal art hobbies may produce sensory stimulation that may look like flow but the application of all characteristics of flow may not be possible in all activities [17].

One respondent had stated that the experience which is the closest to that of practicing yoga is of gardening. She stated that she loved gardening and finds the colours and fragrance of the flowers and the mud appealing. She even stated that she talks to her plants and this overall experience marked her feel 
stress free. Another respondent stated that listening to music created a similarly calming effect as that by yoga. She stated that she paid attention to the lyrics and details of the rhythm thus completely enjoying the experience.

Yet another responded had drawn a parallel between watching films and eating with the experience of yoga. She had stated in her earlier responses that she found the experience of practicing yoga very gripping. She similarly enjoyed the gripping experience of watching films especially thrillers as they managed to grab her complete attention and keep her on the edge. She elaborated on eating by stating that it was an activity she enjoyed as a child. Whenever she eats a dish she tends to enjoy it and tries to understand the spices and ingredients used. She also said that she had been sensitive to proportions of ingredients in the given dish. Stitching and reading were two other activities stated by another participant. She stated that it was not just about stitching new clothes and showcasing her creativity but also doing the same when she noticed a damaged dress or an unused piece of cloth. Yoga also helped her release similar creative energies within her. The experience of yoga she stated also inspire and gave her the strength to fight the odds as does reading autobiographies of great people.

One of the respondent had stated cooking as and activity she enjoys as much as yoga. However she stated that is this the case only when she has lot of time on hand and is not following a strict timeframe. This further emphasizes on the temporal experience characterized in flow. Art and craft had also been stated by a participant. She had stated that painting is soothing and just like yoga can be persuaded in different settings. She also stated that making new things and decorating her house with them had helped her realise her creative potential and enjoy her time. She stayed she felt similarly about yoga. Two respondents had stated activities which maybe largely termed as a part of everyday timetable but had been highlighted as experiences with similariy to that of yoga. One activity is sleeping while the other one is spending time with family. She seems to draw a parallel between the relaxing and calming effect of sleep and yoga. Whereas the other respondent had stated that spending time with her family, talking to them and laughing with them relaxes her and makes her happy just as yoga does. She called the moments she spends with her family as one of her best and said the same about yoga.

Question ten aimed at understanding the application and effect of yoga on the respondents and people around them as evaluated by the respondents. All the respondents agreed that the practice of yoga has been facilitative in a number of positive changes in them and thus has had a similar effect of those associated with them. They have stated that the practice of yoga has made them calmer and helps them control their emotions and thoughts. They are more composed when facing difficult situations and has made them into optimistic problem solvers. This stability and attitudinal change has helped them to be available to others not just physically but mentally. They tend to respond and contribute to conversations by being analytical and empathetic. Their composure makes them feel that they have been more resourceful and supportive to those around them. Lastly the experience of yoga has made them happier as people and thus this reflects in their interactions with people around.

Limitations of this study are that the subjective nature of the construct in study (flow) makes it difficult to quantify and generalize the experiences. The sample includes 10 women practicing yoga. Thus effects due to the gender differences could not be considered. The nature of the stressors has not been considered thus giving no insight regarding their intensity.

\section{CONCLUSIONS}

Limitations of this study are that the subjective nature of the construct in study (flow) makes it difficult to quantify and generalize the experiences. The sample includes 10 women practicing yoga. Thus effects due to the gender differences could not be considered. The nature of the stressors has not been considered thus giving no insight regarding their intensity. The research could be further extended by understanding flow in other schools of Yoga. Populations across various places could be included to further analyse if cultural, social and economic factors contribute in the experience and quality of flow mad its' effect on stress. Tools and techniques for intervention could be developed based on the findings of this study. 


\section{REFERENCES}

1. Schure MB, Christopher J, Christopher S. Mind-body medicine and the art of self- care: teaching mindfulness to counseling students through yoga, meditation, and qigong. J Couns Dev 2008;86(1):47-56.

2. Elson BD, Hauri P, Cunis D. Physiological changes in yoga meditation. Psychophysiology 1977;14(1):52-7.

3. Gimbel MA. Yoga, meditation, and imagery: clinical applications. Nurs Pract Forum 1998;9(4):243-55.

4. Vyas R, Dikshit N. Effect of meditation on respiratory system, cardiovascular system and lipid profile. Indian J Phsyiol Pharmacol 2002;46(4):487-91.

5. Froeliger BE, Garland EL, Modlin LA, McClernon FJ. Neurocognitive correlates of the effects of yoga meditation practice on emotion and cognition: a pilot study. Front Integr Neurosci 2012;6.

6. Csikszentmihalyi M. Flow and the psychology of discovery and invention. New York: Harper Collins; 1996.

7. Csikszentmihalyi M, Csikszentmihalyi IS. Optimal experience: Psychological studies of flow in consciousness. Cambridge university press; 1992.

8. Nakamura J, Csikszentmihalyi M. Flow and the foundations of positive psychology. Springer Netherlands ; 2014.

9. Selye H. Perspectives in stress research. Perspect Biol Med 1959;2(4):403-16.

10. Quick JC, Quick JD, Nelson DL, Hurrell Jr JJ. Preventive stress management in organizations. American Psychological Association; 1997.

11. Greenberg JS. Comprehensive stress management. McGraw-Hill Humanities/Social Sciences/Languages; 2006.

12. Mody BS. Acute effects of Surya Namaskar on the cardiovascular \& metabolic system. J Bodywork Mov Ther 2011;15(3):343-7.

13. Bhavanani $\mathrm{AB}$, Udupa $\mathrm{K}$, Madanmohan PN. A comparative study of slow and fast suryanamaskar on physiological function. Int J Yoga 2011;4(2):71-8.

14. Javadekar P, Manjunath NK. Effect of Surya namaskar on sustained attention in school children. J Yoga Phys Ther. 2012;2:110-6.

15. Waelde LC, Thompson L, Gallagher- Thompson D. A pilot study of a yoga and meditation intervention for dementia caregiver stress. J Clin Psychol 2004;60(6):677-87.

$$
\begin{gathered}
\text { Acknowledgements - Nil; } \\
\text { Source of Funding - Nil } \\
\text { Conflict of Interest - Nil }
\end{gathered}
$$

